\title{
As Malícias orientais de José da Silva Coelho: entre o discurso e o desejo coloniais ${ }^{1}$
}

\author{
Paul Melo e Castro \\ Universidade de Leeds
}

RESUMO: DEBRUÇAMO-NOS NESTE ARTIGO SOBRE AS MALÍCIAS ORIENTAIS, COLETÂNEA DE BREVES TEXTOS SATÍRICOS ESCRITOS EM 1923 PELO GOÊS JOSÉ DA SILVA COELHO E ATÉ AGORA INÉDITOS (PUBLICADO NESTE VOLUME DA VIA ATLÂNTICA, A SEGUIR A SEÇÃO "OUTROS ENSAIOS"). SE NO RESTO DA SUA OBRA SILVA COELHO FOCA A COMUNIDADE CATÓLICA DOS CENTROS URBANOS DA REGIÃO COSTEIRA, AQUI O ESCRITOR CONCENTRA-SE EM PERSONAGENS HINDUS ORIUNDOS DO INTERIOR. ARGUMENTAMOS QUE, NESSA COLETÂNEA, EXISTEM FORTES TRAÇOS DE ATITUDES COLONIAIS E ORIENTALISTAS, ASSIM COMO UM DESEJO MUITO FORTE PELO OUTRO EM TERMOS RELIGIOSOS.

ABSTRACT: THIS ARTICLE DEALS WITH MALICIAS ORIENTAIS, A COLLECTION OF HITHERTO UNPUBLISHED SHORT SATIRIC TEXTS WRITTEN IN 1923 BY THE GOAN AUTHOR JOSÉ DA SILVA COELHO (AND WHICH ARE INCLUDED IN THIS ISSUE OF VIA ATLÂNTICA, FOLLOWING THE SECTION "OUTROS ENSAIOS"). IF IN THE REST OF HIS WORK SILVA COELHO DEALS MAINLY WITH THE URBAN-BASED CATHOLIC COMMUNITY OF THE COASTAL BELT, HERE HE DEPICTS HINDU CHARACTERS ORIGINATING FROM THE HINTERLAND. I ARGUE THAT THE ATTITUDES OF THIS WRITER, IN THIS COLLECTION, BETRAY THE INFLUENCE OF COLONIAL AND ORIENTALIST DISCRIMINATORY THINKING AS WELL AS A PROFOUND DESIRE FOR THE RELIGIOUS, THOUGH NOT RACIAL, OTHER.

PALAVRAS-CHAVES: JOSÉ DA SILVA COELHO, LITERATURA INDO-PORTUGUESA, LITERATURA GOESA DE LÍNGUA PORTUGUESA, CONTO

KEYWORDS: JOSÉ DA SILVA COELHO, INDO-PORTUGUESE LITERATURE, PORTUGUESELANGUAGE GOAN LITERATURE, SHORT STORY

1. Este trabalho foi realizado no âmbito dum Early Career Fellowship da Leverhulme Trust, cujo apoio agradecemos. 
osé da Silva Coelho (1889-1944) não só foi o mais prolífico contista goês ${ }^{2}$ de língua portuguesa mas também o que mais completamente parece ter sido esquecido depois da sua morte. Se na altura em que ele colaborava na imprensa local, entre 1922 e 1927, os seus contos foram muito lidos e imitados, ${ }^{3}$ hoje, na Goa anglófona dos nossos dias, muito poucos conhecem esse autor. ${ }^{4}$ Essa situação é tanto mais paradoxal se pensarmos no apreço em que é tido Francisco João da Costa, o escritor com quem Silva Coelho mais se parece. Costa, conhecido sob o pseudônimo Gip, continua a ser uma referência nas letras e cultura goesas e é amplamente reconhecido pela intelligentsia local, até por pessoas que nunca o leram, e terá ficado ainda mais conhecido depois da sua obra Jacob e Dulce ter sido vertida para o inglês em 2004. As possíveis razões pelas quais Silva Coelho por sua vez caíra no esquecimento são várias. É verdade que o fato de ele nunca ter editado nenhuma coletânea em livro pode ter dificultado o recenseamento e transmissão dos seus escritos. Parece-nos, no entanto, que uma das razões mais importantes pode ser o teor e o estilo das suas narrativas.

Se, por um lado, como escrevem Vimala Devi e Manuel de Seabra, os objetivos literários de Francisco João da Costa e José da Silva Coelho consistiam na "crítica, quase a denúncia do meio social em que viviam" (1971, p. 221), não deixa de ser verdade que o alvo da sátira de Costa era bastante restrito comparado com o seu congênere. Gip, através do retrato da negociação e da concretização dum casamento arranjado, visou a elite católica goesa. Silva Coelho, pelo contrário, não se limita à "fina flor" de Goa, mas investe contra toda a sua sociedade. Nos seus contos, encontramos não só advogados, médicos, funcionários de várias estirpes, batecares e clérigos, que formavam

2. Publicou quase quarenta contos n'O Heraldo, assim como uma recolha de lendas tradicionais do Concão.

3. Seabra escreve: "o fato é que a influência dos seus contos no público foi enorme. O Heraldo, onde vinham publicados, era aguardado com impaciência" (1979, p. 74) e que a popularidade dos seus escritos provocou "uma autêntica febre de contos humorísticos no estilo de José da Silva Coelho" (1979: 80). 4. É verdade que Maria Aurora Couto refere-se a Silva Coelho como "o melhor contista lusófono de Goa" (2007, p. 181), mas ao mesmo tempo na sua bibliografia ela dá o lugar de publicação da Obra quase completa deste escritor como sendo Macau. O fato de que a Obra quase completa foi publicada em Goa no conhecidíssimo embora hoje defunto periódico Boletim de Instituto Menezes Bragança seria óbvio para qualquer um que, de fato, tivesse lido esses escritos. 
a espinha dorsal da sociedade lusitanizada, ${ }^{5}$ mas também manás, bombaístas, peixeiras, cocheiros e colavontas, entre muitos outros. Se na Goa hodierna, uma crítica de espírito anticolonialista a certo servilismo da antiga elite católica face aos modelos comportamentais, linguísticos e vestuários do colonizador é acolhida facilmente, talvez o mesmo não suceda com José da Silva Coelho e seus retratos das pessoas não só da alta burguesia mas também da classe média baixa e dos setores ainda mais populares. Seabra opina que, depois da morte do autor, "como o que escrevia não agradava à sua sociedade, não tardaram em esquecê-lo" (SEABRA, 1979, p. 84). Colocamos a hipótese de que esse esquecimento continua, porque as observações de Silva Coelho ainda podem doer, e doer a todos.

A obscura história da interrupção da publicação da Obra quase completa de José da Silva Coelho no final dos anos 70 talvez seja resultado da natureza problemática dos seus escritos. Depois de se entusiasmar com o trabalho de Silva Coelho ao preparar a importantíssima Literatura Indo-Portuguesa com Vimala Devi, Manuel de Seabra organizou uma compilação de todas as narrativas ficcionais do escritor para o Boletim de Instituto Menezes Bragança, de Goa. Por razões que Seabra desconhece, a publicação foi suspensa a meio. Entre 1979 e 1981 saíram três fascículos da série Contos regionais. Dois anos mais tarde apareceu uma pequena seleção de algumas amostras da série Verdades e mentiras. Os outros escritos de Silva Coelho que Seabra descreve por alto no seu prefácio não chegaram a ver a luz do dia: nem o resto das Verdades e mentiras, nem as Histórias para crianças, nem as Melodias e harmonias, nem as Lendas indianas. ${ }^{6}$ Significativamente, também não foi publicada a coletânea de curtas narrativas que apresentamos aqui: as Malícias orientais. ${ }^{7}$

A história de Silva Coelho é uma história que, até certo ponto, se repete. Devi e Seabra escrevem que o autor continuou a publicar os seus Contos regionais n'O Heraldo até que a sua colaboração teve de ser interrompida depois de

\footnotetext{
5. Silva Coelho também não poupa a população europeia e de eurodescendentes. O conto "O Monserrate" é um dos mais espirituosos retratos do colonizador português semiperiférico que conhecemos na literatura lusófona não metropolitana.

6. Ironicamente, n'A Literatura Indo-Portuguesa Devi e Seabra queixam-se do desleixo votado a essa importante série, observando que as cerca de três dezenas de Lendas Indianas "bem se podiam ter perdido, a julgar pela atenção que lhes foi dada até hoje” (SEABRA, 1971, p. 221).

7. Agradeço profundamente a Manuel de Seabra por me ter cedido o manuscrito original.
} 
terem ofendido profundamente certas pessoas e trazido "dissabores ao seu autor" (DEVI \& SEABRA, 1971, p. 221). Afigura-se que certos textos podem ter atingido pontos fracos aquando da publicação da Obra quase completa no Boletim do Instituto Menezes Bragança. ${ }^{8}$

No entanto, tal como Manuel de Seabra, achamos importante que essas Malícias orientais de Silva Coelho vejam a luz do dia, afim de completar o nosso conhecimento desse intrigante autor goês. Se nos Contos regionais e nas Verdades e mentiras Silva Coelho se concentra na sociedade católica costeira, nas Malícias orientais, Silva Coelho expande o leque da sua "galeria completíssima da vida social de Goa" (DEVI \& SEABRA, 1972, p. 220) de forma a incluir os hindus das Novas Conquistas, território onde o autor residia e trabalhava a serviço do governo local como Notário Público. Ao que parece, Silva Coelho não ousou (talvez temendo "dissabores" com os seus vizinhos) ou simplesmente não conseguiu publicá-los em vida, embora tivesse essa intenção (SEABRA, 1979 , p. 78). Hoje estamos a 84 anos depois do autor ter escrito essas dezesseis narrativas entre 13 de novembro e 20 de dezembro de 1923, quase uma a cada dois dias, "podemos imaginar com uma certa febre" (SEABRA, 1979, p. 77). Neste ano de 2011, em que acontecerá o 50 aniversário da Libertação de Goa do jugo colonial português, cremos ter entrado numa altura propícia para visitar e compreender algumas das partes submergidas do passado. Parece-nos o tempo certo para revisitar essas narrativas, uma vez que os costumes que Silva Coelho objurga já deixaram de ser praticados pela comunidade descrita. Se em vida Silva Coelho não pôde concretizar o desejo de ver esses pequenos textos no prelo, hoje a situação é outra, e temos, dentro e fora de Goa, a objetividade de apreciar as suas virtudes e analisar os seus defeitos.

O que é interessante nessas Malícias orientais não é tanto a faceta satírica. $\mathrm{Na}$ verdade, comparadas com os Contos regionais e as Verdades e mentiras, a sátira desses escritos é mais chistosa que mordaz. Os pequenos textos somam dezesseis no total, dos quais dez retratam escândalos sexuais. Nessas narrativas, a sátira consiste muitas vezes em revelar hipocrisia, sobretudo em casos de figuras oriundas das castas mais altas da sociedade hindu, frequentando su-

8. Infelizmente a interrupção da publicação da Obra quase completa parece ter levado a que alguns contos tenham desaparecido, nomeadamente "O arrependimento de Subodribai", "O eclipse de Dupodibai" e "O doce sumo de caju". 
jeitos originários dos mais baixos estratos, prática terminantemente proibida pela ideologia castista. Em "O segredo da alparqueira" nós descobrimos que o "puritano e rico suzerano" (p. 184) Xenoim está ligado, contrariando todas as regras de pureza social, a uma alparqueira de "casta ínfima, desprezível e infecta" (p. 184). No texto "Amor de Gounlina", nós vemos Suriagi Ráo Pratapráo Sar Dessay, "o grande senhor e rico fazendeiro" (p. 188) involverse com Rocuminin, a pastorinha "de casta reles", supostamente "um objeto sem valor" (p. 189) mas na realidade alvo da cobiça desse homem importante.

Para Seabra "os contos hindus surgem ou demasiado idealizados (principalmente as mulheres) ou anedóticos" (SEABRA, 1979, p. 77). O crítico português pode ter razão, se o que se busca nesses escritos de Silva Coelho é a veia satírica com que aborda a sua própria comunidade. Nós, por outro lado, achamos muito interesse nessas "histórias eróticas" (SEABRA, 1979, p. 90), únicas na obra de Silva Coelho. Esse interesse emana da maneira como o desejo que retratam anula as fronteiras que supostamente, no contexto da sociedade descrita, deviam formar uma barreira intransponível entre as pessoas, e não só as de casta. Assim a beleza da jovem Coxi em "O segredo da alparqueira" amalgama "o coração do cristão, do moiro, do brâmane, do vanino, do ourives e do marata" (p. 184). Outro exemplo cabal, embora irônico, é "A incredulidade do velho Loeshimou", em que a figura principal toma um rapaz vestido de mulher por um membro do sexo feminino. Aqui o desejo transgride não só as barreiras de classe como as divisões de gênero então existentes.

Essas não são as únicas barreiras categóricas que as Malícias orientais transgridem. A ofensa que esses contos podem causar está na maneira como contradizem a imagem cultural da mulher na sociedade hindu. Segundo Fátima da Silva Gracias, exigia-se tradicionalmente das mulheres hindus em Goa que se devotassem ao marido e à família, segundo o modelo de Sita e de Savitri, que fossem monógamas, fiéis (mesmo que os maridos não fossem), submissas e detentoras de todas as virtudes (GRACIAS, 1996, p. 21). As mulheres retratadas nas narrativas de Malícias orientais desmentem essa imagem idealizada. ${ }^{9}$ $\mathrm{Na}$ história "O jejum do boto", a mulher desse "santo" e "suntuoso e pálido

9. Um paradoxo interessante: nesses contos Silva Coelho atribui aos hindus atitudes e padrões de comportamento que atribuídos estereotipicamente às mulheres da comunidade goesa católica na cultura indiana contemporânea (Newman, 2007, p. 252). 
asceta" (p. 181) reage ao desleixo do marido buscando conforto nos braços dum reles deuly. $\mathrm{Na}$ história "O malsuth da vanina", a mulher do mercador o trai com um vizinho brâmane. São, enfim, retratos de seres humanos, ${ }^{10}$ seres com defeitos e sujeitos a tentações tal como em qualquer comunidade. É de notar, no entanto, que, nas suas variadas abordagens da comunidade católica, Silva Coelho nunca se tenha centrado na vertente sexual da vida cotidiana. Discutiremos adiante as possíveis razões para esse desequilíbrio.

Em termos de formato, as Malícias orientais comparam-se de forma profícua aos Contos regionais e às Verdades e mentiras. Manuel de Seabra vê nas Malícias orientais uma viragem na produção do contista goês. Segundo o crítico português, é aqui que Silva Coelho começa a produzir "uma forma literária ainda mais concisa, na realidade quase aquilo que nos Estados Unidos da América se chama short-shorts ou vignettes" (SEABRA, 1979, 79). Argumentamos que, mais do que short-shorts, gênero extremamente moderno, ou vignettes, que sugerem alguma tonalidade impressionista, Malícias orientais são o que se apelida sketch em inglês, uma espécie de camafeu ou retrato literário que é mais uma descrição realista duma figura do que um enredo.

Anne McClintock sustenta que esse gênero de textos descritivos curtos e fisionômicos fez parte da exploração dos espaços sob controle europeu, formando uma espécie de "gênero imperial" (McCLINTOCK, 1997, p. 81). Aqui defendemos que esses escritos de Silva Coelho são reflexos de um certo "olhar colonial" adotado por um sujeito católico e lusitanizado. A ação colonizadora em todos os espaços sob controle europeu gerou muitos textos semelhantes aos de Silva Coelho, onde o conhecimento é figurado como a penetração masculina de um interior caracterizado como feminino e "velado" como tal. Tal observação assenta bem ao que encontramos nas narrativas das Malícias orientais, nas quais a voz narrativa masculina, a partir duma posição exterior à cena descrita, observa figuras delineadas como outros, muitas vezes devassando a intimidade duma personagem feminina e relatando esse processo como espetáculo.

O que interessa ao leitor contemporâneo, defendemos, é essa posição do narrador. Ao intitular essas pícaras narrativas de Malícias orientais o autor está

10. Há alguns contos que talvez pequem por serem demasiado grosseiros, como "O engano de Luoximibay”, que relata as primeiras e confusas experiências sexuais duma jovem esposa. 
a posicionar-se como "ocidental". Até certo ponto Silva Coelho é geograficamente ocidental, pois o autor é originário das Velhas Conquistas e está a viver e retratar as terras a leste dessa região, as Novas Conquistas, de que os portugueses só se apossaram no século XVIII e que nunca chegaram a transformar do mesmo modo que a região costeira. Mas a ocidentalidade dos textos é muito mais profunda.

À primeira vista, porém, esses contos parecem muito menos ocidentais que a precedente produção goesa em língua portuguesa. Antes de Silva Coelho, no domínio da narrativa curta poucos tinham sido os escritos locais a tratar diretamente a realidade cotidiana e corriqueira. No século XIX, segundo o crítico brasileiro Hélder Garmes, muitas vezes "os goeses colocavam-se no espaço letrado de língua portuguesa como cidadãos portugueses, e, portanto, as marcas de identidade eram socialmente pouco enfatizadas ou valorizadas" (GARMES, 2004, p. 80). Só em umas poucas figuras, como Júlio Gonçalves ou Wenceslau Proença, no conto, vemos o desenvolvimento duma curta narrativa cujo conteúdo poderíamos rotular de "goês". A produção literária de Silva Coelho é inovadora na medida em que reflete um ensejo de produzir literatura em Goa sobre Goa e para goeses.

Dito isso, pensamos que a ocidentalidade das Malícias orientais não consiste no tema, mas no ponto de vista do narrador. Ao retratar a sociedade hindu, Silva Coelho enfoca os elementos que a diferem da cultura lusa, cristocêntrica e ocidental. Por mais ordinários que possam ser os textos, essa inclinação dá-lhes imenso interesse antropológico. Silva Coelho, que falava muito corretamente o concanim, era uma raridade na sua comunidade de então, por conhecer bem a cultura hindu e por contar entre as suas amizades mais próximas pessoas oriundas daquela comunidade (SEABRA, 1979, p. 77). Aqui não só temos uma visão da elite hindu das Novas Conquistas, mas também dos setores mais desfavorecidos, uma faixa demográfica com escassa presença na produção literária colonial como nos lembra Claudia Pereira (2010, p. 130). Destarte entram na literatura lusófona figuras como o boto, o ardass, o deuly, o tari, a bavina e a bailadeira, práticas como o falibachen, a quirtana, o nattók, ${ }^{11}$ típicas do hinterland de Goa assim como detalhes de vestimenta, joalharia e culinária

11.Essas figuras e práticas se encontram explicadas nas notas do texto de Malícias Orientais, que se encontra publicado nesta revista, após a seção "Outros Ensaios". 
pertencentes a uma época agora desaparecida. A utilização do calendário lunisolar hindu para estruturar o sequenciamento da segunda metade das narrativas inclui-se na vertente quase arquivística desses escritos. Além disso, Fátima da Silva Gracias lembra-nos que fontes do período colonial sobre as mulheres goesas, e sobretudo sobre as mulheres não cristãs, são raras (GRACIAS, 1996, p. 13). Nesse aspecto, os skeetches de Silva Coelho contêm informações importantes para compor uma possível história da mulher goesa não cristã.

A questão da relação entre o Ocidente e o Oriente é bastante mais complexa do que à primeira vista pode parecer. A ocidentalidade das Malícias orientais tem a sua mais potente expressão na atitude de certa forma orientalista desses textos. O crítico brasileiro Everton V. Machado já assinalou quanto à obra dum outro escritor goês, Francisco Luís Gomes, um posicionamento que ele qualificou de "orientalismo dum oriental". Aqui compreendemos essa expressão como descrevendo um estado de espírito paradoxal, em que um sujeito oriental descreve um Oriente contiguo à sua comunidade de forma orientalista, colocando-se fora desse mesmo Oriente.

A questão do orientalismo no espaço lusotópico é um tanto problemática. Segundo Edward Said (1978), expoente do termo no seu sentido pós-colonialista, o orientalismo entra em cena quando o Oriente é retratado como o outro do Ocidente, região que Said define como os países centrais da Europa na época colonial e os EUA na época pós-colonial. Na sua obra Orientalism, Said deixa de lado a reação da parte dos próprios orientais e descarta por completo a investigação desse discurso no espaço da língua portuguesa. Esse campo de pesquisa só agora está a ser investigado por acadêmicos lusitanistas. A literatura de e sobre Goa certamente se constitui num fértil acervo para o resgate e análise do orientalismo no espaço lusotópico, fornecendo importantes fontes para estudos comparatistas. Em Goa, por meio da ação transformadora da cristianização levada a cabo sob a alçada dos portugueses (processo que rompeu a ligação automática entre origem étnica indiana e cultura hindu em parte da população do território goês), certa elite católica goesa, de acordo com o argumento de Rochelle Pinto, veio a considerar-se participante no Iluminismo europeu na extensão do imperialismo português e, desse modo, pertencente à esfera do Ocidente (2007, p. 16). O que nós queremos argumentar aqui é que o discurso ocidental sobre o Oriente encontra-se espelhado nesses contos de Silva Coelho sobre as Novas Conquistas, 
autor etnicamente indiano, que nasceu na Índia e teve como língua ancestral o concanim, mas que escreveu, viveu e leu em português (e francês, desconhecendo o inglês). É através dessas línguas coloniais e do seu background de elite católica que José da Silva Coelho entra em contato com a cultura europeia e é até certo ponto interpelado por ela, ao passo que na sua vida cotidiana habita, trabalha e se movimenta entre a comunidade hindu das Novas Conquistas. ${ }^{12}$ Em que, então, consiste o orientalismo de José da Silva Coelho?

O mais persistente tropo no discurso orientalista, segundo Said, é a tentativa de representar o Outro oriental, no duplo sentido de Vertretung e de Darstellung (SAID, 1978, p. 4), ou seja, de descrever oniscientemente e, no processo, retirar a autonomia dos representados a favor da voz representadora. Nessas narrativas de Silva Coelho ${ }^{13}$ é notável que, ao contrário da tendência na evolução do conto moderno (BONHEIM, 1982, p. 20), há, com a crucial exceção do primeiro texto narrado na primeira pessoa, muitos poucos diálogos ou falas diretas por parte dos personagens. Quase tudo é descrição de cenários e relato de ações. A agency e a autorreflexão dos personagens é bastante limitada. São como fantoches que servem de material para a compreensão e a fantasia do narrador que tudo sabe e compreende. De resto, Said argumenta que o orientalista amiúde atribui individualidade e autonomia aos representados, construindo-os como tipos. É o que encontramos nas Malícias orientais. Embora as personagens tenham nomes próprios (o que muitas vezes não acontece no conto), são definidos pela sua profissão de casta e, no caso das figuras femininas, da profissão dos seus esposos.

A finalidade última do orientalismo é colocar o europeu (ou, aqui, o sujeito europeizado) acima dos outros que são descritos. O orientalista, valendo-se da necessidade positivista então em voga de amealhar e produzir conhecimento, arroga-se o direito de devassar a intimidade do outro, controlando-a e subordinando-a. O que entra aqui e, de forma crucial, acaba por minar essa tentativa de estabelecer a superioridade desse narrador, é uma profunda ambivalência entre o eu e o outro. Essa impossibilidade de decidir entre o que devem ser os opostos é expressa nas Malícias orientais na maneira como as nar-

12. Os seus Melodias e Harmonias, onde a paisagem de Goa é descrita ao ritmo da música clássica europeia é outro exemplo do seu posicionamento entre discurso ocidental e realidade oriental.

13. Já os contos que formam os Contos Regionais e as Verdades e Mentiras são bastante diferentes, muito mais "modernos". 
rativas mesclam zombaria e atração. Segundo Robert Young todo o discurso colonialista se traía pelo que ele chama "desejo colonial", termo utilizado por ele para indicar o quanto o discurso colonialista tinha infuso um desejo proibido do outro (YOUNG, 1995, p. 1). Esse desejo encontrava expressão, por exemplo, na secreta, mas insistente, obsessão, por parte do romance colonialista pelos encontros sexuais transgressores de fronteiras. Young conclui que nisso traíam um desejo oculto de, unindo-se ao outro, prescindir da própria cultura (YOUNG, 1995, p. 3).

$\mathrm{Na}$ escrita de Silva Coelho os estímulos desse desejo colonial são parte integrante da sua visão orientalizante. Uma das maneiras pelas quais o Ocidente tem representado o Oriente é como um espaço onde reina o oposto da "moralidade de ferro judaico-cristã" (PEREZ, 2005, p. 129). Segundo Said, ao Oriente, como outro, imputou-se uma imagem de sensualidade, de prazer lascivo. O Oriente torna-se um lugar de sexualidade abundante e ilimitada, onde se permitem relações libertinas, isentas de culpa. Para McClintock, esse processo posiciona o Oriente como um pornotropics (1995, p. 23), uma espécie de laterna-mágica do pensamento onde a Europa (ou aqui, no caso de Silva Coelho, sociedade cristianizada e europeizada) projetou os desejos proibidos. É talvez essa a razão por detrás do enfoque anômalo desses escritos na vida sexual no cotidiano. As Malícias orientais são um espaço onde as fantasias de Silva Coelho brincam desimpedidas, com a exceção importante da primeira narrativa.

O primeiro texto intitulado "O pecado da marata" é o único escrito na primeira pessoa e, com esse pendor aparentemente biográfico, é o que mais cabalmente mostra a ambivalência entre desejo e rejeição. Aqui o narrador parece aliar-se à figura do autor, ${ }^{14}$ ao confessar o seu impulso na direção de um outro em termos de classe, casta e religião, proibido pelos imperativos socioculturais. É de notar que nessa narrativa e nas outras a fascinação recai sobre as mulheres hindus das castas inferiores, o setor da população goesa que mais se esquivou da influência direta do colonizador português e das restritivas determinações da sua religião católica.

Nesse texto o narrador relata como não consegue se desvencilhar da atração pela linda Soraspotibay, uma "Afrodite indiana" (p. 179), de tez morena

14. Manuel de Seabra escreve laconicamente "parece que a mulher hindu exercia sobre ele [Silva Coelho] uma grande fascinação” (SEABRA, 1979, p. 86). 
e um pendente dourado ornando o nariz. Será ela o estereotipado objeto feminino do orientalismo, que segundo Said não passa de uma criatura da fantasia masculina, sobre a qual os homens exercem o seu poder, figura de sensualidade ilimitada, figura despida de inteligência e sempre disponíveis fisicamente (SAID, 1978, p. 204). Sim e não. À primeira vista os seus favores sexuais parecem tão fáceis de comprar como as aves que ela cria. No entanto, no decorrer da narrativa, até certo ponto parece-nos que é a Soraspotibay que acaba por estar na mó de cima, conseguindo o que ela quer, enquanto o narrador sofre de desejo e de culpa.

O pecado, ao contrário do que o título sustenta, não é da marata, mas do narrador, que, supomos, representa metonimicamente uma elite católica masculina fascinada pelo proibido polo oposto em termos de sexo, religião, classe e casta, no caso, uma sedutora marata vendedora de franguinhos, figura caracterizada por seus usos e costumes ancestrais, aparentemente isenta de qualquer sentimento de culpa pelas suas ações. É notável que é o narrador que progressivamente perde controle sobre a situação, transformando-se metaforicamente num animal. Incapaz de abdicar do seu desejo, transido de remorso de cariz colonial e judaico-cristão, ele fica "como um animal em cio", farejando "com as ventas dilatadas, a recordação do [...] cheiro fatal" da mulher. Se aqui o narrador se obriga a preterir Soraspotibay, nos outros contos, todos em terceira pessoa, compensa-se ao possuir voyeuristicamente as outras figuras femininas através da narração onisciente. Por um lado, mais do que o personagem masculino com quem se deitam, muitas vezes nem sequer descrito, nos outros contos é sempre o narrador que se deleita na descrição visual da mulher. Por outro lado, nesses contos, a mulher como objeto de desejo partilhado tanto pelo narrador quanto pelo personagem masculino do conto é o ponto onde a divisão entre o narrador onisciente e a comunidade que descreve se dissolve. Se essas narrativas desmentem as barreiras proclamadas na sociedade enfocada, também acabam por diluir a barreira que o narrador tenta erigir entre a sua voz representadora e as figuras representadas. É aqui que a estrutura orientalista das narrativas de Silva Coelho, que visa extrair o narrador e torná-lo superior, tende a ruir.

À medida que a sequência das narrativas avança, e o narrador sacia o seu olhar, começam a aparecer novas situações diegéticas. Se o adultério e o escândalo sexual é o tema das onze primeiras narrativas, a partir da décima se- 
gunda até a penúltima, as histórias viram-se para outros aspectos da vida das mulheres das Novas Conquistas. No singelo "A inveja das flores de lótus", a mulher é simplesmente causa de espanto. $\mathrm{O}$ narrador descreve pasmado o banho em águas frias da jovem Zoiá, cuja beleza faz com que as flores de lótus fiquem "despeitadas e invejosas" (p. 191). Outros contos não são eróticos, dando-nos críticas sóbrias da cena social em que são ambientados. Aqui as mulheres não são sexualizadas, mas objetos de empatia. Se por um lado o retrato que Silva Coelho faz da sociedade hindu é mais lascivo do que as cenas descritas nos Contos regionais, também as Malícias orientais parecem conter, em "O prassad da Bavina", "A visão da Ranina" e "Perfume de flor caída", algumas das suas intervenções mais sinceras. Segundo Manuel de Seabra, "[a] o lado da frivolidade cristã a que pertencia, transmite-nos quase sempre um ambiente trágico ao tratar a comunidade hindu, onde vamos encontrar sentimentos autênticos e profundos, e as únicas páginas verdadeiramente dramáticas que escreveu" (SEABRA, 1979, p. 86).

No entanto, como nos lembra a historiadora americana Julie Stephens, o discurso orientalista sempre se aproveitou do tratamento das mulheres indianas no seio das próprias comunidades para desvalorizar discursivamente a civilização indiana (STEPHENS, 1991, p. 124). Até certo ponto, o que encontramos em Silva Coelho não passa de elementos recorrentes da crítica europeia à sociedade hindu, pelo tratamento dado às mulheres ligadas aos templos, às viúvas e os maus tratos que sofrem as mulheres nos estratos mais baixos da sociedade. Servem esses escritos para afastar e ilibar a voz narradora da fraqueza e derrota do primeiro texto? No texto "O prassad da Bavina" é-nos dada uma previsão do futuro da bailadeira Zaiú. A antropóloga portuguesa Rosa Maria Perez lembra-nos que a bailadeira, ligada a práticas e atitudes que contradiziam a moralidade católica empenhada na domesticação da sexualidade, exercia um enorme fascínio sobre a comunidade católica goesa e europeia, ao passo que também servia de pretexto à critica da sociedade hindu (2005, p. 129). Na visão do narrador, uma vez terminada a vida de prostituta, essa mulher "desprezada pelos homens que a tinham amado morreria ao abandono, olvidada pelo deus a quem servia" (p. 181). A bailadeira, temática obsessiva na literatura goesa de língua portuguesa, é aqui tratada não só como objeto de cobiça, mas também como merecedora de melhor tratamento. Até que ponto, no entanto, essa crítica com a sua assumida superioridade socior- 
religiosa é solapada pelo desejo da "viçosa, delgada e airosa" (p. 181) Zaiú, a que a voz narradora, a avaliar pela descrição, não consegue resistir? É de notar que neste, como em vários outros contos, a figura feminina principal acaba por se deitar, para descrição e deleite do narrador, com um personagem de traços vagamente delineados.

Nos dois textos seguintes, o desejo do narrador desaparece por completo. $\mathrm{Na}$ narrativa "A visão da ranina" é-nos apresentada a triste sina da viúva Chinicula. O tratamento das viúvas sempre foi um pomo de discórdia entre os colonizadores e colonizados no subcontinente indiano, e lugar discursivo de opressão e contestação do domínio imperial. A historiadora goesa Fátima da Silva Gracias resume a vida da mulher de Goa na viuvez assim, em palavras que se aplicam integralmente à situação da pobre Chinicula: a viúva era excluída da sociedade e tratada de forma desumana depois da morte do marido (GRACIAS, 1996, p. 27), sendo que o único papel social que lhes restava era uma vida de "rezar, jejuar e trabalhar na cozinha" (GRACIAS, 1996, p. 27). A historiadora refere-se sobretudo à viuvez como "uma vida cinzenta de celibato forçado" (GRACIAS, 1996, p. 27). É essa perspectiva sem esperança que vemos no final da narrativa, que deixa a protagonista entregue a uma visão do seu defunto esposo:

E a triste Chinicula, de joelhos, curvando a fronte, devotamente, beijando-lhe as sandálias de fios d'oiro, suavemente, nos seus lábios vermelhos só sente as lajes frias da sua reclusão, o pó da terra, as cinzas do Amor - enquanto mocho, piando dolente, lhe recorda que as núpcias dela serão com a Morte, e só com a Morte!... (p. 193).

No texto "O perfume da flor caída", vemos a vida de casada de Kalian (o nome, ironicamente, quer dizer "fortuna" em concanim), que tem por marido um velho bateleiro alcoólatra e brutal. Apesar das suas qualidades pessoais, ela está enjaulada na própria vida. É uma história desoladora, e o seu fado é o de ver a própria "alma incompreendida" cair "no lodaçal da vida, no pântano de podridão" (p. 190). É talvez a mais triste das Malícias orientais.

Se nesses contos as personagens femininas são retratadas com compaixão, existem ainda duas narrativas em que a psicologia da mulher é descrita de forma negativa. Numa dessas narrativas, "O crime da bandorina", o compor- 
tamento da mulher é de certo modo compreensível, uma vez que a protagonista, aparentemente não tendo conseguido produzir um filho, ${ }^{15}$ se vê preterida por uma nova mulher. Ela jubila quando um feroz vendaval aterroriza a primeira noite que a nova mulher partilha o marido. Em "A consolação da Dessaina" um tufão devastador assola o palmar da protagonista. Inicialmente ela fica desolada pelo sucedido, mas acaba por extrair uma satisfação do fato de que a propriedade da vizinha é ainda mais devastada. Aqui é um caso de pura Schadenfreude.

No fundo há uma contradição nas Malícias orientais. Por mais que o narrador, depois do primeiro conto, procure construir uma posição exterior aos acontecimentos que narra, superior àquilo que descreve, nunca deixa de comungar dos impulsos e desejos de todas as figuras envolvidas. Para Ashcroft, Griffith e Tiffin esse condicionalismo encontra-se em todo o discurso colonial. De acordo com sua leitura das ideias de Homi Bhabha, o outro só pode ser construído a partir de elementos recolhidos do eu, mas ao mesmo tempo o eu se vê na obrigação de constituir o outro como irremediavelmente diferente (ASCHCROFT, GRIFFITH, TIFFIN, 1989, p. 102). Esse paradoxo está na base da ambivalência que invade toda a experiência colonial. Aqui temos um fenômeno semelhante do lado de lá da divisão entre colonizador e colonizado, onde os portugueses e até certo ponto os católicos da elite de assimilados ao poder colonial procuraram erigir uma barreira entre os seguidores de sua fé e os hindus. Se a sátira de Silva Coelho está empenhada em revelar o quanto a separação entre as castas hindus altas e baixas é minada na realidade pelos impulsos humanos, esta, como procuramos demonstrar, não é a única divisão que as Malícias orientais acabam por desconstruir. A separação maniqueísta entre um mundo cristão, lusitanizado e ocidental e outro hindu, ancestral e oriental revela-se impossível de manter. Apesar da posição de exterioridade e superioridade assumida pela voz narrativa, podemos dizer que as Malícias orientais resultam da experiência do que Mary Louise Pratt chama de "zona de contacto"16 (PRATT, 1996, p. 6) entre a elite católica lusitanizada posicionada no topo da hierarquia colonial a que José da

15. A lei colonial permitia aos homens hindus tomarem uma nova esposa se a primeira não lhe dava um filho nos primeiros dez anos de casada.

16. Pratt define este espaço social como lugar de encontro e conflito entre culturas díspares, muitas vezes se relacionando em circunstâncias assimétricas de dominação e subordinação (1992, p. 4). 
Silva Coelho pertencia e a comunidade hindu das Novas Conquistas de que se separou no rescaldo da invasão dos portugueses. Por mais que o narrador proteste no primeiro texto, parece-nos que, ao final das contas, e no último conto, "A quirtana de Deuquibay", em que, ao lado do ardass, ou predicante hindu, a voz narradora queda-se fascinada pela visão da "farta e provocadora carne descoberta" duma mulher, o desejo colonial sobreleva-se ao discurso colonialista desse oriental.

\section{Referências Bibliográficas}

ASHCROFT, Bill; GRIFFITHS, Gareth; TIFFIN, Helen. The Empire Writes Back: Theory and Practice in Post-colonial Literatures. London/New York: Routledge, 1989. BONHEIM, Helmut. The Narrative Modes: Techniques of the Short Story. Cambridge: DS Brewer, 1982.

COUTO, Maria Aurora. Literature and History. In: Metabistory: history questioning history. Charles J. Borges; SJ and MN Pearson (Org.). Lisboa: Nova Vega, 2007. p.175-183.

DEVI, Vimala; SEABRA, Manuel. A Literatura indo-portuguesa. Lisboa: Junta de Investigações do Ultramar, 1971.

GARMES, Hélder. Origem e estabelecimento da imprensa e da literatura em Goa. In: Oriente, engenho e arte. GARMES, Hélder (Org.). São Paulo: Alameda, 2004. p. 15-85.

McCLINTOCK, Anne. Imperial Leather: Race, Gender and Sexuality in the Colonial Context. London/New York: Routledge, 1995.

NEWMAN, Robert S. Myths of Goa: Old and New. In Metahistory: history questioning history. Charles J. Borges, SJ and MN Pearson (Org.). Lisboa: Nova Vega, 2007. p.247-256.

PEREIRA, Claudia. Negociações identitárias dos Gaudde de Goa: política de classificação de tribos. Portuguese Literary and Cultural Studies. Massachusetts, n. 17/18 (2010). p. 129-39.

PEREZ, Rosa Maria. The Rhetoric of Empire: Gender Representations in Portuguese India. Portuguese Literary and Cultural Studies. Massachusetts, n. 21:1 (2005), p. 126-141.

PINTO, Rochelle. Between Empires: Print and Politics in Goa. Oxford: Oxford University Press, 2007.

PRATT, Mary Louise. Imperial Eyes: Travel Writing and Transculturation. London/ New York: Routledge, 1992. 
SAID, Edward. Orientalism. London/New York: Routledge, 1978.

SEABRA, Manuel. Prefácio à obra quase completa de José da Silva Coelho. Boletim do Instituto Menezes Bragança. Nova Goa, n. 124, p. 55-124, 1979.

SILVA GRACIAS, Fátima da. Kaleidoscope of Women in Goa 1510-1961. Nova Delhi: Concept Publishing Company, 1996.

STEPHENS, Julie. Feminist Fictions: A Critique of the Category 'Non-Western Women' in Feminist Writings on India. In: RANAJIT, Guha (Org.). Subaltern Studies VI: Writing on South Asian History and Society. Nova Delhi: Oxford University Press, 1992, p. 92-125.

YOUNG, Robert. Colonial Desire: Hybridity in Theory, Culture and Race. London/ New York: Routledge, 1995.

Recebido em 10/02/2011 e aprovado em 10/03/2011. 